\title{
Airways inflammation among workers in a paper industry
}

\author{
R. Rylander*, J. Thorn*, R. Attefors**
}

Airways inflammation among workers in a paper industry. R. Rylander, J. Thorn, R. Attefors. C) ERS Journals Ltd 1999.

ABSTRACT: Exposure to organic dusts may cause airways inflammation in a large proportion of exposed persons. Most studies have relied on questionnaires and spirometry for diagnosis. To assess the possibility of determining the presence of inflammation using clinical diagnostic procedures, a study was undertaken among workers in a paper industry.

Participants were 83 workers and 44 controls. Airborne endotoxin and $(1 \rightarrow 3)-\beta$ D-glucan levels at the worksites were determined. The effects of this exposure were evaluated using a questionnaire, spirometry and measurements of airway responsiveness (methacholine) and levels of eosinophil cationic protein (ECP), myeloperoxidase (MPO), and C-reactive protein (CRP) in serum.

The workers had a decreased baseline forced expiratory volume in one second (FEV1) and an increased airway responsiveness compared with controls. The concentrations of ECP and MPO were elevated compared with controls. There was a relation between exposure to endotoxin and $(1 \rightarrow 3)$ - $\beta$-D-glucan and airway responsiveness as well as ECP levels, when controlling for age, sex, smoking habits, atopy and asthma.

The results suggest an increased prevalence of subjective respiratory symptoms, and an increased airway responsiveness among exposed workers. There was also a relationship between the serum concentration of eosinophil cationic protein and airway responsiveness. Taken together, the results suggest the presence of airways inflammation in the workers.

Eur Respir J 1999; 13: 1151-1157.
*Dept of Environmental Medicine, University of Gothenburg, and **Hyltehälsan Inc, Hyltebruk, Sweden.

Correspondence: R. Rylander

Dept of Environmental Medicine

Box 414

40530 Gothenburg

Sweden

Fax: 4631825004

Keywords: Airways inflammation endotoxin

$(1 \rightarrow 3)-\beta$-D-glucan organic dusts

Received: September 41997

Accepted after revision December 261998

This study was supported by funds from the Swedish Work Environment Fund (contract 94-0505) and Stora Hylte.
There is increasing evidence that diseases and symptoms caused by organic dusts are mainly those involving inflammation. A previous analysis of the symptoms present after exposure to cotton dust, byssinosis, revealed characteristics related to inflammation of the airways such as dry cough, narrowing of the airways after an acute exposure and increased airway responsiveness [1]. A study among farmers demonstrated the presence of symptoms of inflammation as well as increased airway responsiveness, most marked among those working with swine and other animals [2]. These symptoms may be present, although spirometry yields normal values [3].

Organic dusts contain several agents capable of inducing inflammation of the airways. The most widely researched of these are bacterial endotoxins and $(1 \rightarrow 3)-\beta$-D-glucan, a cell wall component in fungi, certain bacteria and plants. A number of symptoms observed after organic dust exposure have been related to the endotoxin concentration in a doseresponse fashion, and a relation between the levels of endotoxin in cotton and grain dust and airway responsiveness has been reported $[4,5]$. Guidelines for environmental endotoxin exposure have been suggested [6].

The paper industry is one example of an occupational environment where organic dusts are generated. Earlier investigations have shown that changes in respiratory function occur at relatively high levels of exposure to paper dust [7]. In the initial stages of paper manufacture, how- ever, a mixture of potentially toxic agents is also present, including micro-organisms. Assessments of exposure to chemicals, airborne dust, micro-organisms and endotoxins have been performed in six Danish paper recycling plants [8], and airborne concentrations of dust, microorganisms and endotoxins were found to vary widely between plants. In general, endotoxin levels were low, but were high in one plant when reuse of process water was intensified. In another study, the nasal cavities of many workers, particularly those in the debarking units, contained high numbers of Klebsiella pneumoniae, coliforms, yeasts and moulds. Bacteria and yeast found in the nose were largely derived from the mill and debarker air, where they mainly originated from process water [9].

The present study was undertaken during the initial processing phase at a paper manufacturing plant. Over the years, there had been numerous complaints of respiratory symptoms and fatigue from the workers, especially among those working in the bark cleaning unit (BCU). Earlier measurements of chemical agents $(\alpha$-pinene, $\beta$-pinene, 3 carene and hydrogen sulphide) had not shown increased levels, but the concentrations of endotoxins were high. The purpose of this study was to assess airways inflammation among the workers, and to assess the relationships between clinical symptoms, markers of inflammation, airway responsiveness and exposure to airborne endotoxin and $(1 \rightarrow$ 3)- $\beta$-D-glucan. 


\section{Materials and methods}

\section{Area of paper mill investigated}

The part of the paper mill investigated processes timber and recycled paper. The timber is brought into enormous tumblers, where the bark is removed in a mechanical process under a spray of water. The timber is shred into small pieces and used for paper production in another part of the plant. Recycled paper is kept in dry storage for 2-4 weeks, whereafter it is ground in water. Chemicals are added and the slurry is washed to remove the printing ink. During all of these processes, an aerosol of waste water and recycled process water is generated.

\section{Population sample}

The study group comprised all persons working in the bark cleaning unit (BCU), the recycled paper storage (RPS), and the recycled paper processing (RPP) unit. Control persons were recruited from the local municipal administration, mainly office workers, and from a wholesale dealer in the same municipality, mainly storemen but also office workers. They were largely similar to the workers in terms of sex and social and educational background.

Three controls and two subjects working in the paper mill were excluded because they had worked $<1 \mathrm{yr}$ in the present workplace and had previously worked in a dusty environment. Two control subjects were excluded because they were exposed to organic dusts. One worker was excluded because of a serious pulmonary disease. Subjects with colds were not examined at that time, but after recovery.

Data on the number of persons invited, participants in the study and their background characteristics are presented in table 1.

The proportion of atopic subjects (see below) was lower among workers, but the difference was not significant. There was a significantly higher proportion of asthmatics among subjects with a positive Phadiatop test (Pharmacia Diagnostics, Uppsala, Sweden) (atopic) as compared with those with a negative Phadiatop test (nonatopic) (13 versus $1 \%, \mathrm{p}<0.01)$.

To assess turnover, employment data were collected between 11 June, 1987 and 31 October, 1995. In the BCU, 19 workers left their jobs during this period, one retired and ten transferred to other sites in the industry. One worker left the RPS unit and six left the RPR unit. These subjects were not included in the study.

Exposure measurements and investigations of subjects were made between 31 October, 1995 and 2 April, 1996. All investigations of any one subject were made on the same day, first a blood sample was taken, then the subject was interviewed using a questionnaire, and finally tests of lung function and airway responsiveness were carried out. The tests were performed during an ordinary working week. The examinations of workers were mainly carried out in the afternoon. The examinations of controls were carried out in the afternoon, just after their shift. The area of the mill investigated industry operates $24 \mathrm{~h}, 7$ days. week $^{-1}$ and most of the workers were on a shift system. When performing the examinations of the subjects, they had to have worked $\geq 2$ days in a row.

\section{Exposure}

Measurements of airborne dust for determination of endotoxin and $(1 \rightarrow 3)-\beta$-D-glucan levels were made by drawing air through Isopore filters (ATTP $0.8 \mu \mathrm{m}$; Millipore, Cambridge, MA, USA) at a flow rate of $5 \mathrm{~L} \cdot \mathrm{min}^{-1}$ for 30 min. Sampling involved 12 filters in the BCU, four in the RPP unit and four in the RPS unit. Two filters were placed in the area between the RPP and RPS units. The number of filters placed in each worksite were chosen for practical reasons, and according to the different sizes of the worksites. The exposure for an individual subject was identified as being the average exposure recorded on the filters placed in the close vicinity of the subject's working environments, i.e. not as the mean exposure of the worksite. The filters were shaken for $10 \mathrm{~min}$ in $10 \mathrm{~mL}$ pyrogenfree water. A sample was set aside for later endotoxin analyses. Thereafter, $1 \mathrm{~mL}$ of $0.3 \mathrm{M} \mathrm{NaOH}$ was added to 1 $\mathrm{mL}$ washing solution, and the filters were shaken on ice for 10 min to unravel the triple helix structure of the glucan and make it water soluble. The extraction solution from the filters was analysed for endotoxin and $(1 \rightarrow 3)$ - $\beta$-D-glucan content using specific limulus lysates [10]. Filter extract samples of $50 \mu \mathrm{L}$ were placed in a microwell plate, and

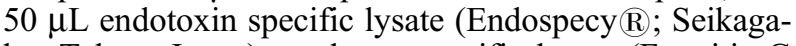
ku, Tokyo, Japan) or glucan specific lysate (Fungitic G Test $(\mathbb{B}$; Seikagaku) were added. The plate was incubat-

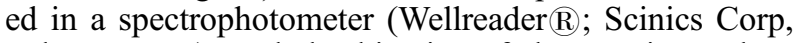
Tokyo, Japan), and the kinetics of the ensuing colour reaction was read photometrically, transformed into absorbance units and compared to a standard curve. The results were expressed as $\mathrm{ng} \cdot \mathrm{mL}$ liquid $^{-1}$. Using the flow

Table 1. - Population characteristics of controls and workers in the bark cleaning unit (BCU), recycled paper processing (RPP) unit and recycled paper storage (RPS) unit

\begin{tabular}{lllcc}
\hline & Controls & BCU & RPP unit & RPS unit \\
\hline Persons invited n & 68 & 52 & 34 & 10 \\
Participants n (\%) & $44(65)$ & $48(92)$ & $28(82)$ & $7(70)$ \\
Age, mean (range) yrs & $40(22-59)$ & $39(20-60)$ & $39(19-61)$ & $47(28-57)$ \\
Males n (\%) & $34(77)$ & $43(90)$ & $26(93)$ & $6(86)$ \\
Smokers n (\%) & $4(9)$ & $16(33)$ & $9(32)$ & $2(29)$ \\
Working time, mean (range) yrs & $8(0.2-30)$ & $11(2-22)$ & $13(0.2-46)$ & $12(4-22)$ \\
Physician-diagnosed asthma n (\%) & $4(9)$ & $1(2)$ & $1(4)$ & $1(14)$ \\
Positive Phadiatop test n (\%) & $19(43)$ & $15(31)$ & $8(29)$ & $3(43)$ \\
\hline
\end{tabular}


rate of air through the filter, this value was transformed to $\mathrm{ng} \cdot \mathrm{m}^{-3}$. The detection limit for this technique is 10 $\mathrm{pg} \cdot \mathrm{mL}^{-1}$ for endotoxin and $20 \mathrm{pg} \cdot \mathrm{mL}^{-1}$ for $(1 \rightarrow 3)-\beta-\mathrm{D}-$ glucan.

\section{Spirometry and airway responsiveness}

Spirometry was performed using standard techniques. A Vitalograph model S (Vitalograph Ltd., Buckingham, UK) with a pulmonary function test printer was used and calibrated every morning using a 1-L syringe. The subjects performed at least three technically acceptable trials, and the largest value of forced expiratory volume in one second (FEV1) was record and compared with predicted values [11].

Airway responsiveness was assessed using the methacholine challenge test according to YAN et al. [12] with some modifications. Spirometry was performed to exclude subjects with FEV1 and/or FEV1/forced vital capacity (FVC) values of $<70 \%$ predicted. A Pari Boy nebulizer (Pari Inhalierboy, Sverup, Gothenburg, Sweden) with automatic dosing was calibrated to an output of $3 \mu \mathrm{L} \cdot \operatorname{dose}^{-1}$. The subjects exhaled to slightly less than functional residual capacity, placed the nebulizer in their mouth and started to inhale. At maximum inhalation, the breath was held for $3 \mathrm{~s}$ before exhaling. One min after inhalation, the maximum FVC and FEV1 were recorded.

The subjects initially inhaled one dose of saline. The spirometric values obtained $1 \mathrm{~min}$ after this inhalation were used as baseline values for the methacholine test. Methacholine was administered in increasing doses at 3-min intervals to a total of $1.2 \mathrm{mg}$. FVC and FEV1 were recorded 1 min after each dose of methacholine. In subjects in which FEV1 decreased by $>10 \%$ of the baseline value after one dose, a slower increase in dose levels was administered. If FEV1 decreased by $>20 \%$ of the baseline value after any dose of methacholine, the test was discontinued. The results were expressed as the group mean decrease in FEV1 after the highest dose of methacholine administered. A decrease in FEV1 was identified as an increase in airway responsiveness.

\section{Inflammatory markers and atopy in serum}

Eosinophil cationic protein (ECP), myeloperoxidase (MPO) and C-reactive protein (CRP) were determined in serum (Clinical Allergy Laboratory at Sahlgren's Hospital, Gothenburg, Sweden). ECP was assayed by means of a fluorescence enzyme immunoassay (FEIA) technique (CAP ECP FEIA; Pharmacia Diagnostics), MPO by a radioimmunoassay (RIA) technique (CAP MPO RIA; Pharmacia Diagnostics) and expressed in $\mu \mathrm{g} \cdot \mathrm{L}^{-1}$. CRP was assayed by the Mancini technique (Behringer Mannheim, Mannheim, Germany), and expressed in $\mu \mathrm{g} \cdot \mathrm{mL}^{-1}$.

Atopy was assayed via an FEIA technique (CAP Phadiatop FEIA, Pharmacia Diagnostics). The results were expressed as being positive (atopic) or negative (nonatopic). The Phadiatop test is an in vitro test system based on ImmunoCAP technology for the determination of immunoglobulin (Ig)E specific to inhaled allergens in human serum. A mixture of 10 relevant inhaled allergens, covalently coupled to ImmunoCAP ${ }^{\mathrm{TM}}$ (Pharmacia Diagnostics), reacts with the specific IgE in the patient's serum speci- men. After washing away nonspecifically bound $\operatorname{IgE}$, enzyme-labelled (fluorescent) antibodies directed against bound $\operatorname{IgE}$ are added to form a complex. The fluorescence is measured and compared with a reference serum sample. The within assay coefficient of variation is $5-7 \%$ and cross-reactivity with other human Igs is non-existent at physiological concentrations of $\operatorname{IgA}, \operatorname{IgD}$, IgM and IgG according to the manufacturer. Atopy is defined as a reaction above a certain limit against any of these 10 inhaled allergens. The test is well characterized and has been used in previous studies $[13,14]$. The sensitivity and specificity are 0.91 and 0.93 , based on 21 studies. This test is used for the clinical diagnosis of atopy in Sweden, Denmark, Norway, Finland, the Netherlands, Germany and England amongst others.

\section{Questionnaire}

The subjects were interviewed using a questionnaire for the assessment of organic dust-induced effects, which has been used in several previous investigations [15]. It contained a series of items on existing diseases, previous work in a dusty environment, length of employment at the present worksite, physician-verified allergy and smoking habits. This was followed by a series of questions on different symptoms, present at least one-third of the time. The symptoms were cough, dry or with phlegm, chest tightness, shortness of breath, irritation in the eyes, nose or throat and nose congestion and itchy nose. Questions were also posed regarding joint pains, muscle pains, headache, unusual tiredness, skin problems and lower gastrointestinal symptoms. Special questions related to subjective airway reactivity and chronic bronchitis, which was defined as having cough with sputum for $\geq 3$ months $\cdot \mathrm{yr}^{-1}$ for a period of $\geq 2 \mathrm{yrs}$. Asthma was defined as physician-diagnosed asthma. Based on previous experience, the question "Have you, during the past 6 months, had episodes of flu-like symptoms such as fever, chills, malaise, muscle or joint pains, and perhaps also cough, breathlessness and weakness, and felt completely well the following day?" was also posed.

\section{Statistical analysis}

The differences between subjects working in the investigated mill and controls were analysed using the Student's t-test and one-way analysis of variance for comparison of group means. If normal variation was not present, nonparametric tests (Mann-Whitney U-test and Chi-squared test) were used.

For categorical variables, logistic regression analyses were performed to compare workers and controls, and to evaluate the relationships between endotoxins and $(1 \rightarrow 3)$ $\beta$-D-glucan exposure and the different categorical variables. Crude as well as adjusted odds ratios with 95\% confidence intervals (CIs) were computed while controlling for age, sex, cigarette smoking status and atopy. CRP level was treated as a categorical variable, because it was not a true continuous variable, and the cut-off level chosen was $1 \mu \mathrm{g} \cdot \mathrm{mL}^{-1}$. For the continuous variables, linear regression analyses were performed, crude and adjusted for age, sex, cigarette smoking status and atopy. For baseline FEV1 (\% pred), the results were expressed as mean 
differences $(\Delta)$ with $95 \%$ CIs. ECP and MPO level data were not normally distributed, and the data were therefore logarithmically transformed before performing the analyses. The results were then back-transformed and expressed as percentage differences on the original scale $(\Delta \%)$ with $95 \%$ CIs.

The airway responsiveness data were not normally distributed and contained negative values. The values were therefore treated as positive values for the logarithmic transformation. To achieve a satisfactory normal distribution after the logarithmic transformation, 10 was the smallest positive value that could be used (10-FEV1 values). The percentage differences for the airway responsiveness data $(\Delta \%)$ with $95 \%$ CIs were reported on the transformed scale. As a consequence of this transformation, these values are approximate. There is also an underestimation of the percentage differences between the groups on the original scale.

The number of asthmatics in the investigated population was small (four among controls and three among workers) and the regression analyses were only performed on nonasthmatics. Differences were considered statistically significant at $p<0.05$. In view of the relatively small number of workers, no subanalysis of different working sites could be made.

The study was approved by the Ethics Committee of the Faculty of Medicine in Gothenburg.

\section{Results}

\section{Exposure conditions}

The results of the determinations of airborne endotoxins and $(1 \rightarrow 3)-\beta$-D-glucan at the different worksites are found in table 2. The BCU contained the highest levels. Between the others, endotoxin levels were highest in the RPP unit and $(1 \rightarrow 3)-\beta$-D-glucan levels highest in the RPS unit. There was a significant correlation between the amounts of airborne endotoxin and $(1 \rightarrow 3)-\beta$-D-glucan $(\mathrm{r}=0.93 ; \mathrm{p}<0.001)$.

\section{Spirometry and airway responsiveness}

The baseline FEV1 values (\% pred) were significantly lower among workers as compared to controls (mean \pm SD $96 \pm 15$ versus $103 \pm 12 \%, \mathrm{p}<0.01$ ), with similar results among nonsmokers, nonsmokers/nonasthmatics and nonatopics, but not among atopics, where the reduction in FEV1 was not significant.

Table 2. - Concentrations of airborne endotoxin and $(1 \rightarrow$ $3)$ - $\beta$-D-glucan in the bark cleaning unit (BCU), recycled paper processing (RPP) unit, recycled paper storage (RPS) unit and worksites of controls

\begin{tabular}{|c|c|c|c|c|c|}
\hline & \multirow{2}{*}{$\begin{array}{c}\text { Filters } \\
n\end{array}$} & \multicolumn{2}{|c|}{$\begin{array}{l}\text { Endotoxin } \\
\mathrm{ng} \cdot \mathrm{m}^{-3}\end{array}$} & \multicolumn{2}{|c|}{$\begin{array}{c}(1 \rightarrow 3)-\beta-\mathrm{D}-\text { Glucan } \\
\mathrm{ng} \cdot \mathrm{m}^{-3}\end{array}$} \\
\hline & & Mean & Range & Mean & Range \\
\hline $\mathrm{BCU}$ & 12 & 97.7 & $23-220$ & 240 & $49-366$ \\
\hline RPP unit & 4 & 18.2 & $4-45$ & 10 & $5-15$ \\
\hline RPS unit & 4 & 2.0 & $0-5$ & 38 & $4-75$ \\
\hline Controls & 8 & 0.1 & $0-0.8$ & 4 & $0-13$ \\
\hline
\end{tabular}

The methacholine challenge test was performed by $85 \%$ of the workers and $93 \%$ of the controls. Of those who performed the test, there were four workers who could not be administered the highest dose of methacholine because they reacted with a sharp drop in FEV1 after a previous dose. The reduction in FEV1 after the highest dose of methacholine was significantly greater among workers than among controls $(-8.0 \pm 7.0$ versus $-4.0 \pm 4.9 \%, \mathrm{p}<0.01)$, with similar results among nonsmokers, nonsmokers/nonasthmatics, nonatopics and atopics. The reduction in FEV1 was independent of the number of years worked.

\section{Inflammatory markers in serum}

The concentration of ECP in serum was significantly higher among workers than among controls (7.7 \pm 5.7 versus $\left.5.1 \pm 2.7 \mu \mathrm{g} \cdot \mathrm{L}^{-1}, \mathrm{p}<0.01\right)$. Approximately the same proportional differences were found for the concentration of MPO (345 \pm 138 versus $\left.279 \pm 82 \mu \mathrm{g} \cdot \mathrm{L}^{-1}, \mathrm{p}<0.01\right)$, with similar results among nonsmokers, nonsmokers/nonasthmatics, nonatopics and atopics. The concentration of CRP was slightly decreased among workers as compared with controls $\left(2.3 \pm 2.7\right.$ versus $3.6 \pm 5.0 \mu \mathrm{g} \cdot \mathrm{L}^{-1}$, Ns).

\section{Questionnaire data}

In general, a higher proportion of workers reported symptoms as compared with controls. The differences were significant for unusual tiredness (45 versus 16\%, $\mathrm{p}<0.01)$, joint pains $(27$ versus $5 \%, \mathrm{p}<0.01)$ and nasal irritation ( 28 versus $5 \%, \mathrm{p}<0.01)$, with similar results among nonsmokers and nonsmokers/nonasthmatics/nonatopics.

A higher proportion of workers reported episodes of flulike symptoms which had vanished completely the following day as compared with controls (27 versus $5 \%, \mathrm{p}<$ 0.01 , with similar results among nonsmokers and nonsmokers/nonasthmatics. There were no differences between workers and controls regarding chronic bronchitis.

\section{Regression analyses}

Linear regression analyses were performed for the continuous variables (ECP levels, MPO levels, airway responsiveness and baseline FEV1) between workers and controls, and against airborne endotoxins and $(1 \rightarrow 3)-\beta$ D-glucan. ECP concentration $\left(\mu \mathrm{g} \cdot \mathrm{L}^{-1}\right), \mathrm{MPO}\left(\mu \mathrm{g} \cdot \mathrm{L}^{-1}\right)$ and airway responsiveness $(\%$ change $)$ were significantly higher and baseline FEV1 values (\% pred) significantly lower among workers as compared with controls $(\Delta \%=38.3$, $\mathrm{CI}=23.0-75.6, \mathrm{p}<0.01 ; \Delta \%=19.4, \mathrm{CI}=4.3-36.6, \mathrm{p}<0.05$; $\Delta \%=28.9, \mathrm{CI}=13.8-46.2, \mathrm{p}<0.001$ and $\Delta=-6.3 ; \mathrm{CI}=-11.5-$ $-1.0, \mathrm{p}<0.05$, respectively). ECP levels, MPO levels and airway responsiveness were also significantly higher among workers as compared with controls, when controlling for age, sex, cigarette smoking status and atopy $(\Delta \%$ $=48.7, \mathrm{CI}=15.7-91.1, \mathrm{p}<0.01 ; \Delta \%=23.5, \mathrm{CI}=7.0-42.5, \mathrm{p}<$ $0.01, \Delta \%=34.2, \mathrm{CI}=16.5-54.3, \mathrm{p}<0.001$, respectively). Linear regression analyses for the continuous variables in relation to endotoxin exposure are shown in table 3 . ECP concentration and airway responsiveness were increased over the exposure range. MPO concentration was 
Table 3. - Linear regression analyses evaluating the relationship between airbone endotoxin and baseline forced expiratory volume in one second (FEV1), airway responsiveness and serum esosinophil cationic protein (ECP) and myeloperoxidase (MPO) levels

\begin{tabular}{|c|c|c|c|}
\hline & \multicolumn{3}{|c|}{ Endotoxin $\mathrm{ng} \cdot \mathrm{m}^{-3}$} \\
\hline & $0-1$ & $2-20$ & $21-98$ \\
\hline Subjects n & 40 & 33 & 44 \\
\hline \multicolumn{4}{|c|}{ Baseline FEV1 \% pred } \\
\hline Crude & 0 & $-6.4(-12.9-0.1)$ & $-5.8(-11.8-0.2)$ \\
\hline Adjusted & 0 & $-5.1(-11.7-1.4)$ & $-4.8(-10.9-1.3)$ \\
\hline \multicolumn{4}{|c|}{ Airway responsiveness \% } \\
\hline Crude & 0 & $19.1(2.4-38.5)^{*}$ & $35.7(18.0-55.9)^{* * *}$ \\
\hline Adjusted & 0 & $23.5(4.7-45.6)^{*}$ & $40.6(20.7-63.9)^{* * *}$ \\
\hline \multicolumn{4}{|l|}{ ЕСР $\mu \mathrm{g} \cdot \mathrm{L}^{-1}$} \\
\hline Crude & 0 & $33.9(-0.2-79.7)$ & $39.7(6.1-83.7)^{*}$ \\
\hline Adjusted & 0 & $44.8(7.1-95.8)^{*}$ & $47.4(9.2-95.5)^{* *}$ \\
\hline \multicolumn{4}{|l|}{ MPO $\mu \mathrm{g} \cdot \mathrm{L}^{-1}$} \\
\hline Crude & 0 & $25.5(6.4-47.9)^{* *}$ & $14.2(-2.0-33.1)$ \\
\hline Adjusted & 0 & $30.0(9.6-54.1)^{* *}$ & $17.8(0.5-38.1)^{*}$ \\
\hline
\end{tabular}

Values represent mean differences for FEV1 and percentage differences for airway responsiveness and ECP and MPO levels with 95\% confidence intervals in parentheses, controlled for age, sex, cigarette smoking status and atopy (adjusted data; crude data are not controlled for these variables). For further details see Statistical analysis. ${ }^{*}: \mathrm{p}<0.05 ;{ }^{* *}: \mathrm{p}<0.01 ; * * * \mathrm{p}<0.001,0-1 \mathrm{ng} \cdot \mathrm{m}^{-3}$ as reference.

increased and baseline FEV1 values decreased as compared with the low exposure group, without a doseresponse trend. The results were similar when controlling for age, sex, cigarette smoking status and atopy. Linear regression analyses for the continuous variables in relation to $(1 \rightarrow 3)-\beta$-D-glucan exposure were similar to those related to endotoxin exposure (data not shown).

The adjusted odds ratios with 95\% CIs for category variables are shown in tables 4 and 5 . The adjusted odds ratios for cough with phlegm, irritation in the nose, congested nose, unusual tiredness, joint pains, and reports of flu-like symptoms were larger among workers as compared with controls. The adjusted odds ratios for cough with phlegm, throat irritation, congested nose, unusual tiredness, joint pains and reports of flu-like symptoms were increased in the high exposure group of endotoxin and $(1 \rightarrow 3)-\beta$-D-glucan. The crude odds ratios with $95 \%$ CIs for category variables were similar to the adjusted odds ratios (data not shown).

Linear regression analyses were performed to evaluate the relationships between ECP concentration, MPO concentration and airway responsiveness. When controlling for age, sex, atopy and cigarette smoking status, ECP concentration was found to relate to airway responsiveness and to MPO concentration $(\mathrm{b} \%=2.6, \mathrm{CI}=0.6-4.8, \mathrm{p}<0.05$; $\mathrm{b} \%=0.3, \mathrm{CI}=0.2-0.4, \mathrm{p}<0.001$, respectively).

\section{Discussion}

This study reports an increased prevalence of subjective respiratory and general symptoms among workers at certain worksites in a pulp/paper mill. In view of previous discussions at the worksites, it cannot be excluded that part of this increase was caused by overreporting of symptoms. The increase in symptomatology was, however, related to objective measurements of inflammation, and overreporting, if present, could thus only partially explain the increase. The number of controls in the study was smaller than the number of workers, but no further controls were available.

The method of evaluating bronchial reactivity used in this study differs from traditional clinical testing methods. Instead of titrating the dose required for a certain effect, e.g. the provocative dose causing a $20 \%$ fall in FEV1, the mean reaction to the highest cumulative dose given in a

Table 4. - Logistic regression analyses evaluating the relationships between workers and controls, airborne endotoxin or $(1 \rightarrow 3)$ - $\beta$-D-glucan and respiratory symptoms

\begin{tabular}{|c|c|c|c|c|c|c|c|}
\hline & $\begin{array}{c}\text { Subjects } \\
\mathrm{n}\end{array}$ & $\begin{array}{l}\text { Throat } \\
\text { irritation }\end{array}$ & $\begin{array}{c}\text { Nose } \\
\text { irritation }\end{array}$ & Dry cough & $\begin{array}{l}\text { Chronic } \\
\text { bronchitis }\end{array}$ & $\begin{array}{l}\text { Cough with } \\
\text { phlegm }\end{array}$ & Congested nose \\
\hline Controls & 40 & 1 & 1 & 1 & 1 & 1 & 1 \\
\hline Workers & 80 & $2.6(0.7-10.0)$ & $19.2(2.3-158.7)$ & $2.9(0.3-31.2)$ & $0.9(0.2-4.0)$ & $3.3(0.8-13.1)$ & $3.8(1.2-11.8)$ \\
\hline \multicolumn{8}{|l|}{ Endotoxin $\mathrm{ng} \cdot \mathrm{m}^{-3}$} \\
\hline $0-1$ & 40 & 1 & 1 & 1 & 1 & 1 & 1 \\
\hline $2-20$ & 33 & $0.7(0.1-4.8)$ & $31.8(3.6-285.7)$ & $8.7(0.5-138.9)$ & $1.3(0.2-6.8)$ & $2.0(0.4-10.5)$ & $3.2(0.9-11.4)$ \\
\hline 21-98 & 44 & $4.6(1.1-19.1)$ & $13.5(1.5-119.0)$ & $1.0(0-22.2)$ & $0.7(0.1-3.9)$ & $4.4(1.0-18.7)$ & $4.6(1.4-15.1)$ \\
\hline \multicolumn{8}{|l|}{ Glucan $\mathrm{ng} \cdot \mathrm{m}^{-3}$} \\
\hline $0-9$ & 35 & 1 & 1 & 1 & 1 & 1 & 1 \\
\hline $10-38$ & 38 & $0.5(0.1-3.3)$ & - & - & $0.9(0.2-5.0)$ & $1.6(0.3-8.1)$ & $2.0(0.5-7.1)$ \\
\hline $39-245$ & 44 & $3.7(0.9-15.9)$ & - & - & $0.6(0.1-3.3)$ & $3.8(0.9-16.9)$ & $3.6(1.1-12.2)$ \\
\hline
\end{tabular}

Values represent adjusted odds ratios with $95 \%$ confidence intervals in parentheses, controlling for age, sex, cigarette smoking status and atopy. 
Table 5. - Logistic regression analyses evaluating the relationships between workers and controls, airborne endotoxin or $(1 \rightarrow 3)$ - $\beta$-D-glucan or general symptoms

\begin{tabular}{|c|c|c|c|c|c|c|}
\hline & $\begin{array}{c}\text { Subjects } \\
\mathrm{n}\end{array}$ & CRP levels & Headache & Joint pains & Unusual tiredness & $\begin{array}{l}\text { Flu-like } \\
\text { symptoms }\end{array}$ \\
\hline Controls & 40 & 1 & 1 & 1 & 1 & 1 \\
\hline Workers & 80 & $1.8(0.7-4.4)$ & $2.0(0.3-11.8)$ & $14.2(1.7-116.3)$ & $4.1(1.5-11.3)$ & $6.3(1.3-29.2)$ \\
\hline \multicolumn{7}{|c|}{ Endotoxin $\mathrm{ng} \cdot \mathrm{m}^{-3}$} \\
\hline $0-1$ & 40 & 1 & 1 & 1 & 1 & 1 \\
\hline $2-20$ & 33 & $2.1(0.7-5.9)$ & $2.5(0.3-18.3)$ & $10.9(1.2-98.0)$ & $2.3(0.7-7.6)$ & $3.6(0.6-19.8)$ \\
\hline $21-98$ & 44 & $1.4(0.5-3.7)$ & $1.7(0.2-12.1)$ & $19.6(2.3-166.7)$ & $5.8(2.0-17.5)$ & $9.9(2.0-48.3)$ \\
\hline \multicolumn{7}{|c|}{ Glucan $\mathrm{ng} \cdot \mathrm{m}^{-3}$} \\
\hline $0-9$ & 35 & 1 & 1 & 1 & 1 & 1 \\
\hline $10-38$ & 38 & $1.4(0.5-4.1)$ & $1.8(0.2-13.4)$ & $9.0(1.0-81.3)$ & $1.6(0.5-5.4)$ & $2.8(0.5-15.4)$ \\
\hline $39-245$ & 44 & $1.1(0.4-3.2)$ & $1.4(0.2-10.6)$ & $18.3(2.1-158.7)$ & $5.0(1.6-15.2)$ & $8.7(1.8-43.5)$ \\
\hline
\end{tabular}

Values represent adjusted odds ratios with $95 \%$ confidence intervals in parentheses, controlling for age, sex, cigarette smoking status and atopy.

relatively short time was calculated. This method was chosen because the clinical method is not suitable for field studies. The same procedure has been used in other similar studies to evaluate the effects of methacholine challenges and relationships to exposure have been shown [2, 4].

The results demonstrated several differences between workers at the paper mill and controls in terms of spirometry, airway responsiveness and symptoms. These results are similar to those found in previous studies on persons exposed to organic dusts in other environments [2, $3,5,16]$ and suggest the presence of inflammation of the airways. They were independent of atopy, suggesting that they were unspecific and not related to antigen sensitization. Further support for the presence of airways inflammation comes from markers of inflammation in serum. Workers had higher levels of ECP and MPO, independent of age, sex, smoking, asthma and atopy. A relationship between ECP concentration and airway responsiveness was found, suggesting that ECP levels in serum reflect changes in the airways. However, the assessment of airways inflammation via levels of inflammatory markers in serum can only be regarded as an indirect evaluation. The present findings need to be verified by means of measuring markers in sputum or bronchoalveolar lavage fluid.

Increased levels of ECP and MPO have been found in previous studies on airways inflammation. In bronchial lavage fluid samples from patients with chronic bronchitis, increased levels of ECP and MPO were found [17]. Serum ECP has been suggested to be a sensitive marker of inflammatory airflow obstruction in chronic asthma [18]. Higher concentrations of sputum ECP in symptomatic asthmatic patients have been reported [19] as well as a correlation between sputum ECP levels and airflow obstruction [20]. Taken together with the results from this study, these studies indicate that ECP and MPO are probably markers related to a nonspecific inflammatory process involving activation of eosinophils and neutrophils. This conclusion is supported by studies on subjects exposed to pure endotoxin (lipopolysaccharide (LPS)) where increased amounts of ECP and MPO were found in induced sputum [21, 22].

Several workers reported flu-like symptoms such as fever, shivering, dry cough, fatigue and muscle and joint pains. This group of symptoms is often referred to as fever with an environmental determinant, e.g. printer's fever (inhalation fever). The term "organic dust toxic syndrome" has also been used [23]. Inhalation of LPS can cause these symptoms as well as an increased number of neutrophils in the blood and the airways [21, 22]. A decrease in carbon monoxide transfer [24] and an acute invasion of neutrophils into the lung walls of guinea-pigs, with a peak 4-12 h after LPS challenge [25], have previously been reported. These findings suggest inflammation of the airways and lung parenchyma. In view of this, the term "toxic pneumonitis" has been suggested [6].

Relationships were found between the amount of airborne endotoxin and several of the effect variables. From a mechanistic point of view, these relationships are reasonable. After inhalation, endotoxins induce a series of intracellular changes in macrophages, which can be collectively referred to as activation. This activation results in the production of chemotactic factors. It has been shown that neutrophil invasion in the lung results from the secretion of chemotactic agents by alveolar macrophages [26]. Endotoxin-induced activation of macrophages also results in an increased production of different cytokines, such as interleukin- 1 and tumour necrosis factor- $\alpha$.

$(1 \rightarrow 3)-\beta$-D-glucan was also related to several of the effect variables. As there was a close relationship between endotoxin and $(1 \rightarrow 3)$ - $\beta$-D-glucan exposure, it is not possible to conclude which of the two agents was the most relevant. In view of previous endotoxin measurements, the abundance of information on endotoxin, its relations with several effects among exposed persons and the suggested guidelines for exposure [6], this agent is currently the best indicator for the observed effects.

In the present study, the environmental measurements focused on endotoxin and $(1 \rightarrow 3)-\beta$-D-glucan. The aerosols of process water in the paper mill and particles from bark and wood and other constituents of the exposure may contain several other bioactive agents [7]. Previous workplace measurements of $\alpha$-pinene, $\beta$-pinene, 3 -carene and hydrogen sulphide had however not shown increased values. Recent measurements in the BCU of the amounts of airborne terpenes and hydrogen sulphide, performed after this study but in the same season, again showed very low values (data not shown).

In conclusion, the results suggest an increased prevalence of subjective respiratory symptoms and more reports of flu-like symptoms ("toxic pneumonitis") among 
workers exposed to an aerosol containing endotoxin and $(1 \rightarrow 3)-\beta$-D-glucan. The workers had an increased airway responsiveness as compared with controls. There was also a relationship between the amount of serum eosinophil cationic protein and airway responsiveness. Taken together, these results suggest the presence of airways inflammation.

\begin{abstract}
Acknowledgements. The assistance of K. Franzon, A. Lindqvist and all participants are gratefully acknowledged. The authors thank K. Torén for valuable comments.
\end{abstract}

\section{References}

1. Rylander R, Schilling RSF, Pickering CAC, Rooke GB, Dempsey AM, Jacobs RR. Effects after acute and chronic exposure to cotton dust: the Manchester criteria. Br J Ind Med 1987; 44: 577-579.

2. Carvalheiro ME, Peterson Y, Rubenowitz E, Rylander R. Bronchial reactivity and work-related symptoms in farmers. Am J Ind Med 1995; 27: 65-74.

3. Donham KJ. Health effects from work in swine confinement buildings. Am J Ind Med 1990; 17: 17-25.

4. Rylander R, Bergström R. Bronchial reactivity among cotton workers. Ann Occup Hyg 1993; 37: 57-63.

5. Schwartz DA, Thorne PS, Yagla SJ, et al. The role of endotoxin in grain dust induced lung disease. Am J Respir Crit Care Med 1995; 152: 603-608.

6. Rylander R, Jacobs RR, eds. Endotoxins in the environment - a criteria document. Int J Occup Environ Health 1997; 3: S1-S48.

7. Torén $\mathrm{K}$, Hagberg S, Westberg H. Health effects of working in pulp and paper mills: exposure, obstructive airways diseases, hypersensitivity reactions, and cardiovascular diseases. Am J Ind Med 1996; 29: 111-122.

8. Rix BA, Lynge E. Industrial hygiene measurements in a new industry: the repulping and deinking of paper waste. Am J Ind Med 1996; 30: 142-147.

9. Niemela SI, Vaatanen P, Mentu J, Jokinen A, Jappinen P, Sillanpaa P. Microbial incidence in upper respiratory tracts of workers in the paper industry. Appl Environ Microbiol 1985; 50: 163-168.

10. Tamura H, Arimoto Y, Tanaka S, Yoshida S, Obayashi T, Kawal T. Automated kinetic assay for endotoxin and $(1 \rightarrow 3)-\beta-D-g l u c a n$ in human blood. Clin Chim Acta 1994; 226: $109-112$.

11. Knudson RJ, Lebowitz MD, Holberg CJ, Burrows B. Changes in normal maximal expiratory flow-volume curve with growth and aging. Am Rev Respir Dis 1983; 127: $725-734$.
12. Yan K, Salome C, Woolcock AJ. Rapid method for measurements of bronchial responsiveness. Thorax 1983; 38: 760-765.

13. Matricardi PM, Nisini R, Pizzolo JG, D'Amelio R. The use of Phadiatop $(\mathbb{R}$ in mass-screening programmes of inhalant allergies: advantages and limitations. Clin Exp Allergy 1990; 20: 151-155.

14. Thorn J, Beijer L, Rylander R. Airways inflammation and glucan exposure among household waste collectors. $\mathrm{Am} \mathrm{J}$ Ind Med 1998; 33: 463-470.

15. Rylander R, Peterson Y, Donham KJ. Questionnaire evaluating organic dust exposure. Am J Ind Med 1990; 17: 121-126.

16. Sigsgaard T, Malmros P, Nersting L, Petersen C. Respiratory disorders and atopy in Danish refuse workers. Am J Respir Crit Care Med 1994; 149: 1407-1412.

17. Riise GC, Ahlstedt S, Larsson S, et al. Bronchial inflammation in chronic bronchitis assessed by measurement of cell products in bronchial lavage fluid. Thorax 1995; 50: 360-365.

18. Wever AMJ, Wever-Hess J, Hensgens HESJ, Hermans J. Serum eosinophil cationic protein (ECP) in chronic asthma. Relationship to spirometry, flow-volume curves, PC20 and exacerbations. Respir Med 1994; 88: 613-621.

19. Konno S, Gonokami Y, Kurokawa M, et al. Cytokine concentrations in sputum of asthmatic patients. Int Arch Allergy Immunol 1996; 109: 73-78.

20. Virchow JC, Hölscher U, Virchow C. Sputum ECP levels correlate with parameters of airflow obstruction. Am Rev Respir Dis 1992; 146: 604-606.

21. Michel O, Nagy AM, Schroeven M, et al. Dose-response relationship to inhaled endotoxin in normal subjects. Am J Respir Crit Care Med 1997; 156: 1157-1164.

22. Thorn J, Rylander R. Inflammatory response after inhalation of bacterial endotoxin assessed by the induced sputum technique. Thorax 1998; 53: 1047-1053.

23. Von Essen S, Robbins RA, Thompson AB, Rennard SI. Organic dust toxic syndrome: an acute febrile reaction to organic dust exposure distinct from hypersensitivity pneumonitis. J Toxicol Clin Toxicol 1990; 28: 389-420.

24. Herbert A, Carvalheiro MF, Rubenowitz E, Bake B, Rylander R. Reduction of alveolar-capillary diffusion after inhalation of endotoxin in normal subjects. Chest 1992; 102: 1095-1098.

25. Venaille $\mathrm{T}$, Snella MC, Holt P, Rylander R. Cell recruitment into lung wall and airways of conventional and pathogen-free guinea pigs after inhalation of endotoxin. Am Rev Respir Dis 1989; 139: 1356-1360.

26. Snella MC. Production of a neutrophil chemotactic factor by endotoxin stimulated macrophages in vitro. Br J Exp Pathol 1986; 67: 801-807. 